\title{
Comparison of Cache Page Replacement Techniques to Enhance Cache Memory Performance
}

\author{
Pancham \\ M.Tech, Student \\ IET Alwar, Rajsthan, India
}

\author{
Deepak Chaudhary \\ Assistant Professor \\ IET Alwar, Rajsthan, India
}

\author{
Ruchin Gupta \\ Assistant Professor \\ AKGEC, Ghaziabad, India
}

\begin{abstract}
Caching is a very important technique for improving the computer system performance, it employed to hide the latency gap between memory and the CPU by exploiting locality in memory accesses. In modern computer architectures a page miss cause the several hundred CPU cycles $[1,15]$. In a memory hierarchy, a cache performs faster than auxiliary storage, but is more expensive. Some important page replacement policies such as FIFO, LRU, RANDOM and SECOND CHANCE are used in cache memory to replace the page whenever it is needed. So page replacement policy severely affects the performance of cache memory. So here our purpose is to simulate FIFO, LRU, RANDOM and SECOND CHANCE policies and to compare the results for various applications such as bzip, swim and gcc traces (taken from SPEC2000 benchmark for simulation) etc. using MS-Excel [3, $10,12]$.
\end{abstract}

\section{General terms}

Computer Architecture, Operating system, cache memory, main memory and Performance evaluation of system

\section{Keywords}

Cache performance, page replacement policies, page faults, MS-Excel, C-language

\section{INTRODUCTION}

In modern computer Architecture Page replacement is an important part of an operating system. When we needed a page, it is searched in translation look aside buffers (TLB) or page tables and if found missing from main memory a page fault will be occur. The size of the cache memory smaller than auxiliary memory $[4,5]$. The role of the page replacement is to identify the page to evict from main memory when page fault occur and replace it by new page from disk than contains requested datum or instruction. The problem is very common to the block replacement in cache memories but the page replacement is more critical as page transfers from disk to memory with respect magnitudes slower than block transfers from main memory to cache memory. Many page replacement policies are derived and tested. Some of them include Fist-in-First-out (FIFO), least recently used (LRU), RANDOM and SECOND CHANCE. Good page placement policies reduced the page faults cost resulting in higher performance. Since the more page faults the operating system encounters the more resources are wasted in paging in/out instead of doing useful work. And resulting it causes the serious thrashing problems. In this paper, we present the relative competitive analysis of the following page replacement policies including FIFO, LRU, RANDOM and SECOND CHANCE. The relative competitive performances of the page replacement policy are relative to the performance of another policy [14, 19].

\section{REPLACEMENT ALGORITHMS}

Let us briefly explain the basic definition of the replacement policies for the preparation of this paper $[12,19]$ :

\subsection{First in, First out (FIFO)}

In first-in-first out page replacement policy, when a page is needed,

the page that has been in memory for the longest period of time is chosen to replace. The rationale is that a page that has only recently been swapped in will have a higher probability of being used again soon. However a frequently used page still gets swapped out when it gets to be old enough, even though it will have to be brought in again immediately $[8,19]$.

\subsection{Least Recently Used (LRU)}

Least recently used page replacement policy is based on past aspect is a mirror of the pattern in the near future. Pages that have been accessed recently are likely to continue to be accessed and ought to be kept in physical memory. An allocated memory page of a program will become a replacement candidate if the page has not been accessed for a certain period of time under two conditions: (1) the program does not need to access the page; and (2) the program is conducting page faults (a sleeping process) so that it is not able to access the page although it might have done so without the page faults. However, LRU page re- placement implementations do not discriminate between two types of LRU pages and treat them equally. So it means that LRU can be made closer to optimal policy by making improvement into that $[9,19]$.

\subsection{Random Replacement (RR)}

It randomly selects the particular page and discards it to make space when necessary. This algorithm does not require any information to access history. For its simplicity it is used for ARM processors. Random replacement policy randomly replaces the page in memory when it needed. This eliminates the overhead cost to tracking the page references. Usually it is better than FIFO policy and for looking memory reference it is better than LRU but generally LRU perform better result in practice. Generally OS/390 uses LRU replacement but when LRU performance degenerate it fall back to Random replacement. Intel i860 processor used a random replacement policy [11, 19].

\subsection{Second Chance Replacement (SR)}

In Second Chance page replacement policy, the pages for removal are consider in a round robin manner, and a page that has been accessed between consecutive considerations will not 
be replaced. The page replaced is the one that considered in a round robin matter has not been accessed since its last consideration[16, 17].

\section{Second Chance Implementation algorithm:}

1. Add a "second chance" bit to each memory frame.

2. Each time a memory frame is referenced, set the "second chance" bit to ONE (1) - this will give the frame a second chance.

3. A new page read into a memory frame has the second chance bit set to ZERO (0)

4. When you need to find a page for removal, look in a round robin manner in the memory frames:

- If the second chance bit is ONE, reset its second chance bit (to ZERO) and continue.

- If the second chance bit is ZERO, replace the page in that memory frame.

\section{SIMULATOR}

The proper choice of a page replacement algorithm is actually quite a complex matter. To make the proper choice, we must know something about real applications. How do they really access memory? Do they generate many page accesses in order? To answer these questions, we must see what real applications do. In this, paper evaluates how real applications respond to a variety of page replacement algorithms. Modifying a real operating system to use different page replacement algorithms is quite a technical mess, so it will make this by simulation. We write a program that simulates the behaviour of a memory system using a variety of page replacement algorithms. We obtain memory traces from real applications so that we can evaluate algorithm properly. Here the purpose is to build a simulator that reads a memory trace and simulates the action of a cache memory with a single level page table in single programming model. The simulator keeps track of what pages are loaded into memory [6]. As it processes each memory event from the trace, it should check to see if the corresponding page is loaded. If not, it should choose a page to remove from memory. Assume that all pages and page frames are $4 \mathrm{~KB}$ etc. It implements different page replacement algorithms such as FIFO, LRU RANDOM and SECOND CHANCE. The simulator is written in plain C in MS-DOS environment It assumes that reference string is containing six thousands references stored in an array. Numbers of frames are varied and no of page faults are calculated. Reference strings of different applications are taken as input and numbers of page faults are calculated and graphs are plotted in MS-EXCEL between no. of frames vs. no. of page faults $[2,3,18]$.

\subsection{Memory Traces}

Each trace obtained from Internet is a real recording of a running program, taken from the SPEC2000 benchmarks. Real traces are enormously big having billions and billions of memory accesses. However, a relatively small trace will be more than enough. Each trace only consists of one million memory accesses taken from the beginning of each program. Traces are gcc.trace.gz, swim.trace.gz, bzip.trace.gz Each trace is a series of lines, each listing hexadecimal memory addresses followed by $\mathrm{R}$ or $\mathrm{W}$ to indicate a read or a write.

For example, gcc.trace trace starts like this:

0041f7a0R 13f5e2c0R 05e78900R 004758a0R

\section{SIMULATION RESULTS}

We executed several programs for 9 different no. of frame size and compared it with DIRECT, FIFO, LRU, RANDOM and SECOND CHANCE page replacement policies. As we compared the page faults for above policies in table 10 , table 11 , and table12 for standard traces bzip, swim and gcc the performance of the policies are varied. We assume that all pages, frames size are $3 \mathrm{~KB}$ and $1 \mathrm{~KB}$ etc. and reference string of size 3 thousand $[7,13]$.

\section{Table 1 (for Direct mapping)}

\begin{tabular}{|c|c|c|c|}
\hline $\begin{array}{c}\text { No. of } \\
\text { frames }\end{array}$ & $\begin{array}{c}\text { Page faults for } \\
\text { bzip.txt }\end{array}$ & $\begin{array}{c}\text { Page faults for } \\
\text { swim.txt }\end{array}$ & $\begin{array}{c}\text { Page faults for } \\
\text { gcc.txt }\end{array}$ \\
\hline 3 & 811 & 1404 & 1931 \\
\hline 7 & 696 & 1113 & 1519 \\
\hline 15 & 580 & 849 & 1302 \\
\hline 31 & 465 & 480 & 1141 \\
\hline 63 & 393 & 367 & 993 \\
\hline 127 & 331 & 340 & 878 \\
\hline 255 & 300 & 219 & 787 \\
\hline 511 & 282 & 218 & 716 \\
\hline 1023 & 265 & 179 & 672 \\
\hline
\end{tabular}

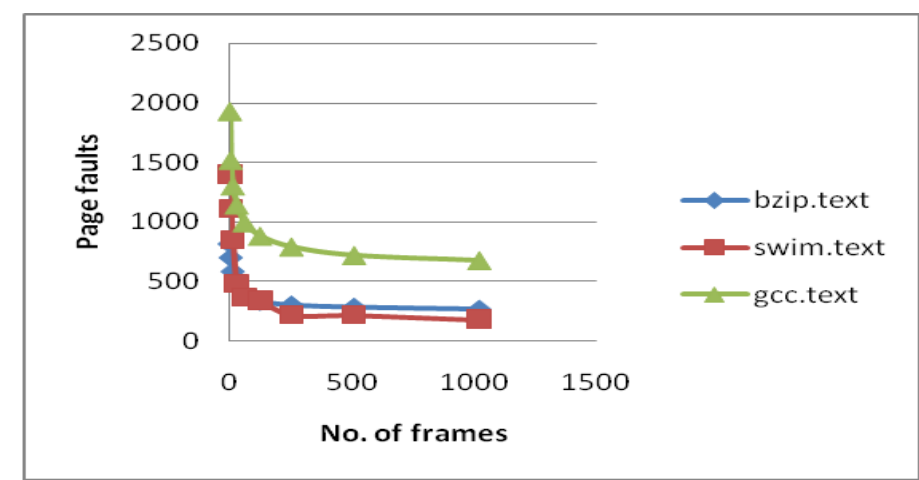

Figure 1 (for Direct mapping)

Table 2 (for FIFO associative mapping)

\begin{tabular}{|c|c|c|c|}
\hline $\begin{array}{c}\text { No. of } \\
\text { frames }\end{array}$ & $\begin{array}{c}\text { Page faults for } \\
\text { bzip.txt }\end{array}$ & $\begin{array}{c}\text { Page faults for } \\
\text { swim.txt }\end{array}$ & $\begin{array}{c}\text { Page faults for } \\
\text { gcc.txt }\end{array}$ \\
\hline 3 & 719 & 1397 & 1826 \\
\hline 7 & 579 & 1131 & 1415 \\
\hline 15 & 472 & 832 & 1121 \\
\hline 31 & 378 & 319 & 928 \\
\hline 63 & 329 & 125 & 858 \\
\hline 127 & 278 & 82 & 828 \\
\hline 255 & 244 & 82 & 803 \\
\hline 511 & 244 & 82 & 575 \\
\hline 1023 & 244 & 82 & 571 \\
\hline
\end{tabular}

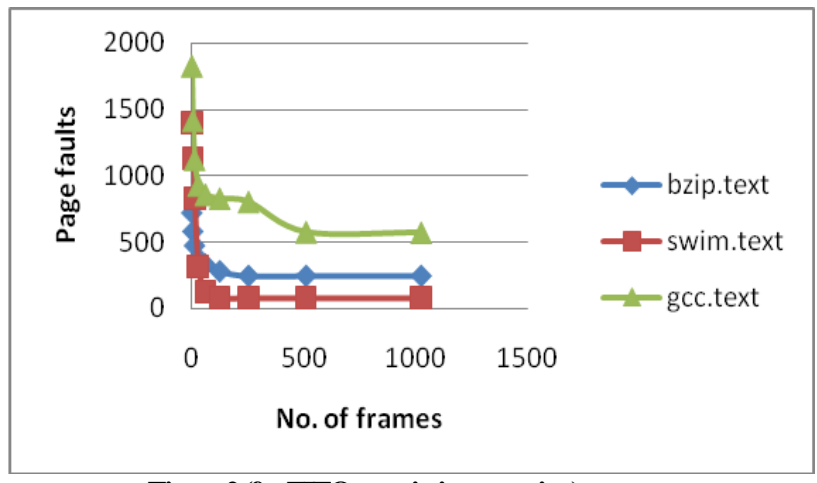

Figure 2 (for FIFO associative mapping) 
Table3(for FIFO Set-associative mapping)

\begin{tabular}{|c|c|c|c|}
\hline $\begin{array}{c}\text { No. of } \\
\text { frames }\end{array}$ & $\begin{array}{c}\text { Page faults } \\
\text { for bzip.txt }\end{array}$ & $\begin{array}{c}\text { Page faults for } \\
\text { swim.txt }\end{array}$ & $\begin{array}{c}\text { Page faults for } \\
\text { gcc.txt }\end{array}$ \\
\hline 3 & 719 & 1397 & 1826 \\
\hline 7 & 600 & 1142 & 1428 \\
\hline 15 & 483 & 765 & 1145 \\
\hline 31 & 402 & 355 & 977 \\
\hline 63 & 352 & 221 & 905 \\
\hline 127 & 292 & 132 & 838 \\
\hline 255 & 259 & 98 & 756 \\
\hline 511 & 248 & 86 & 636 \\
\hline 1023 & 244 & 82 & 585 \\
\hline
\end{tabular}

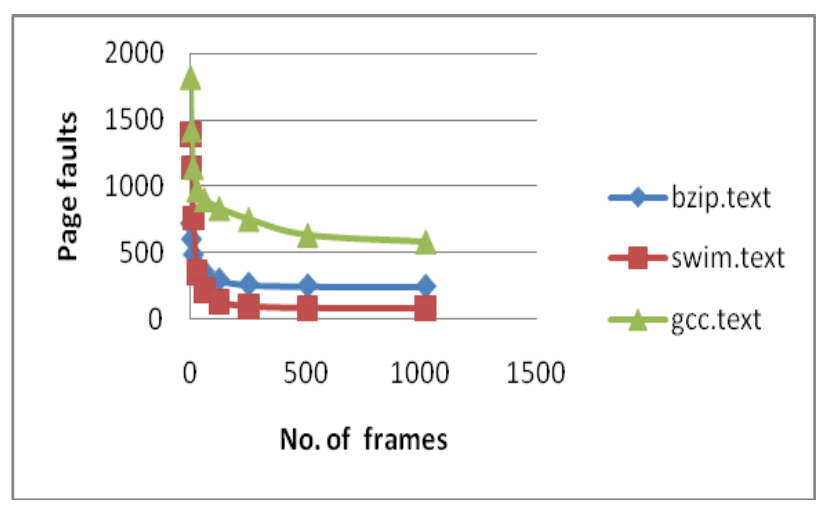

Figure 3(for FIFO Set-associative mapping)

Table4 (for LRU associative mapping)

\begin{tabular}{|c|c|c|c|}
\hline $\begin{array}{c}\text { No. of } \\
\text { frames }\end{array}$ & $\begin{array}{c}\text { Page faults for } \\
\text { bzip.txt }\end{array}$ & $\begin{array}{c}\text { Page faults } \\
\text { for swim.txt }\end{array}$ & $\begin{array}{c}\text { Page faults } \\
\text { for gcc.txt }\end{array}$ \\
\hline 3 & 682 & 1143 & 1737 \\
\hline 7 & 549 & 1009 & 1272 \\
\hline 15 & 447 & 687 & 1007 \\
\hline 31 & 368 & 173 & 886 \\
\hline 63 & 313 & 95 & 849 \\
\hline 127 & 275 & 82 & 819 \\
\hline 255 & 244 & 82 & 796 \\
\hline 511 & 244 & 82 & 573 \\
\hline 1023 & 244 & 82 & 571 \\
\hline
\end{tabular}

\begin{tabular}{|c|c|c|c|}
\hline \begin{tabular}{|c|c|} 
Fo. of \\
frames
\end{tabular} & $\begin{array}{l}\text { Page faults } \\
\text { for bzip.txt }\end{array}$ & $\begin{array}{l}\text { Page faults for } \\
\text { swim.txt }\end{array}$ & $\begin{array}{l}\text { Page faults for } \\
\text { gcc.txt }\end{array}$ \\
\hline 3 & 682 & 1143 & 1737 \\
\hline 7 & 571 & 995 & 1310 \\
\hline 15 & 457 & 660 & 1054 \\
\hline 31 & 378 & 263 & 938 \\
\hline 63 & 335 & 179 & 888 \\
\hline 127 & 287 & 117 & 830 \\
\hline 255 & 257 & 91 & 752 \\
\hline 511 & 247 & 84 & 630 \\
\hline 1023 & 244 & 82 & 583 \\
\hline
\end{tabular}

Table 5 (for LRU Set-associative mapping)

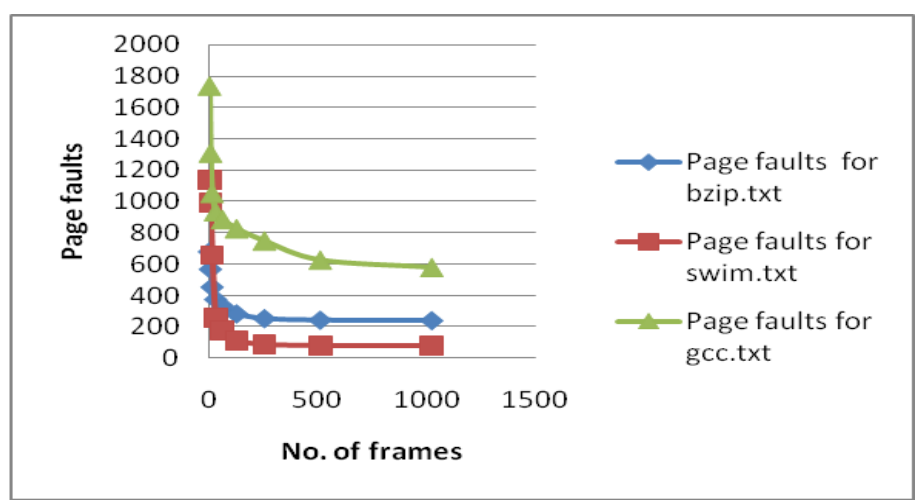

Figure 5 (for LRU Set-associative mapping)

Table 6 (for RANDOM associative mapping)

\begin{tabular}{|c|c|c|c|}
\hline $\begin{array}{c}\text { No. of } \\
\text { frames }\end{array}$ & $\begin{array}{c}\text { Page faults for } \\
\text { bzip.txt }\end{array}$ & $\begin{array}{c}\text { Page faults for } \\
\text { swim.txt }\end{array}$ & $\begin{array}{c}\text { Page faults for } \\
\text { gcc.txt }\end{array}$ \\
\hline 3 & 760 & 1425 & 1846 \\
\hline 7 & 620 & 1127 & 1475 \\
\hline 15 & 545 & 713 & 1278 \\
\hline 31 & 449 & 304 & 1140 \\
\hline 63 & 347 & 118 & 961 \\
\hline 127 & 274 & 82 & 836 \\
\hline 255 & 244 & 82 & 731 \\
\hline 511 & 244 & 82 & 574 \\
\hline 1023 & 244 & 82 & 571 \\
\hline
\end{tabular}




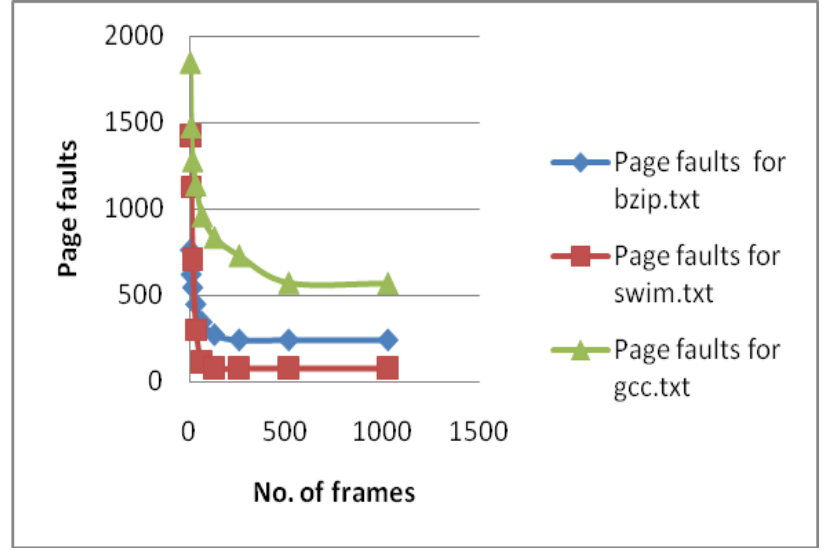

Figure 6(for RANDOMassociative mapping)

Table 7 (for RANDOMSet-associative mapping)

\begin{tabular}{|c|c|c|c|}
\hline No. of frames & $\begin{array}{c}\text { Page faults for } \\
\text { bzip.txt }\end{array}$ & $\begin{array}{c}\text { Page faults for } \\
\text { swim.txt }\end{array}$ & $\begin{array}{c}\text { Page faults } \\
\text { for gcc.txt }\end{array}$ \\
\hline 3 & 760 & 1425 & 1846 \\
\hline 7 & 645 & 1116 & 1478 \\
\hline 15 & 497 & 703 & 1216 \\
\hline 31 & 438 & 338 & 1041 \\
\hline 63 & 353 & 189 & 977 \\
\hline 127 & 302 & 153 & 870 \\
\hline 255 & 257 & 93 & 747 \\
\hline 511 & 246 & 86 & 631 \\
\hline 1023 & 244 & 82 & 578 \\
\hline
\end{tabular}

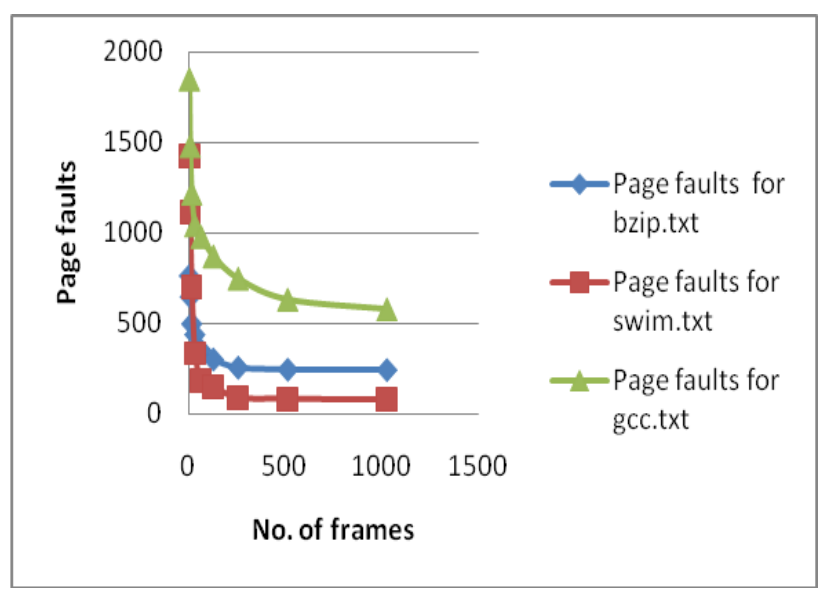

Figure 7 (for RANDOM Set-associative mapping)

Table 8(for SECONDCHANCE associative mapping)

\begin{tabular}{|c|c|c|c|}
\hline No. of frames & $\begin{array}{c}\text { Page faults for } \\
\text { bzip.txt }\end{array}$ & $\begin{array}{c}\text { Page faults } \\
\text { for swim.txt }\end{array}$ & $\begin{array}{c}\text { Page faults } \\
\text { for gcc.txt }\end{array}$ \\
\hline 3 & 688 & 1155 & 1699 \\
\hline 7 & 558 & 979 & 1253 \\
\hline 15 & 446 & 617 & 995 \\
\hline 31 & 367 & 168 & 893 \\
\hline
\end{tabular}

\begin{tabular}{|c|c|c|c|}
63 & 317 & 91 & 849 \\
\hline 127 & 281 & 82 & 820 \\
\hline 255 & 244 & 82 & 693 \\
\hline 511 & 244 & 82 & 574 \\
\hline 1023 & 244 & 82 & 571 \\
\hline
\end{tabular}

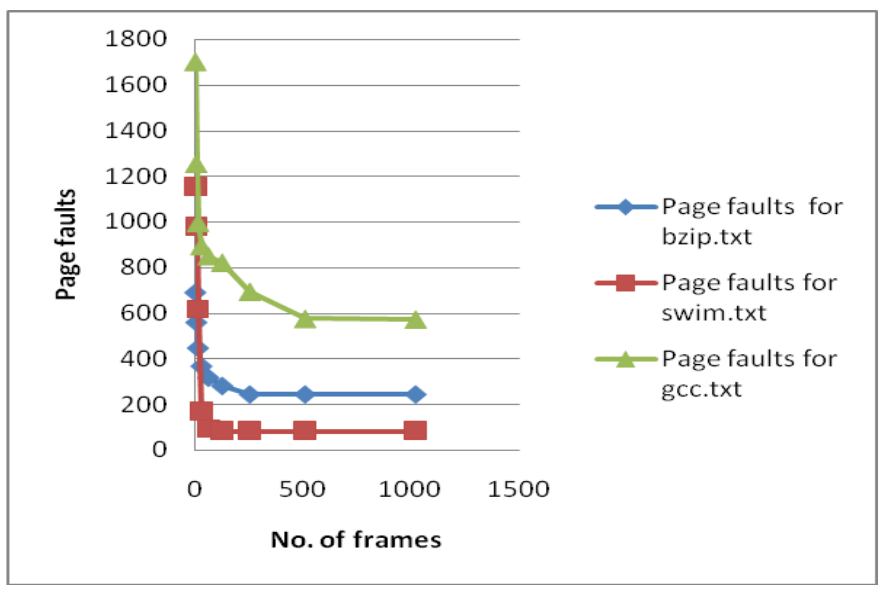

Figure 8(forSECOND CHANCEassociative mapping)

Table9 (for SECONDCHANCESet-associative mapping)

\begin{tabular}{|c|c|c|c|}
\hline No. of frames & $\begin{array}{c}\text { Page faults for } \\
\text { bzip.txt }\end{array}$ & $\begin{array}{c}\text { Page faults } \\
\text { for swim.txt }\end{array}$ & $\begin{array}{c}\text { Page faults } \\
\text { for gcc.txt }\end{array}$ \\
\hline 3 & 688 & 1155 & 1699 \\
\hline 7 & 568 & 979 & 1324 \\
\hline 15 & 473 & 586 & 1095 \\
\hline 31 & 399 & 277 & 968 \\
\hline 63 & 357 & 206 & 903 \\
\hline 127 & 312 & 121 & 852 \\
\hline 255 & 278 & 101 & 761 \\
\hline 511 & 259 & 100 & 686 \\
\hline 1023 & 256 & 93 & 629 \\
\hline
\end{tabular}

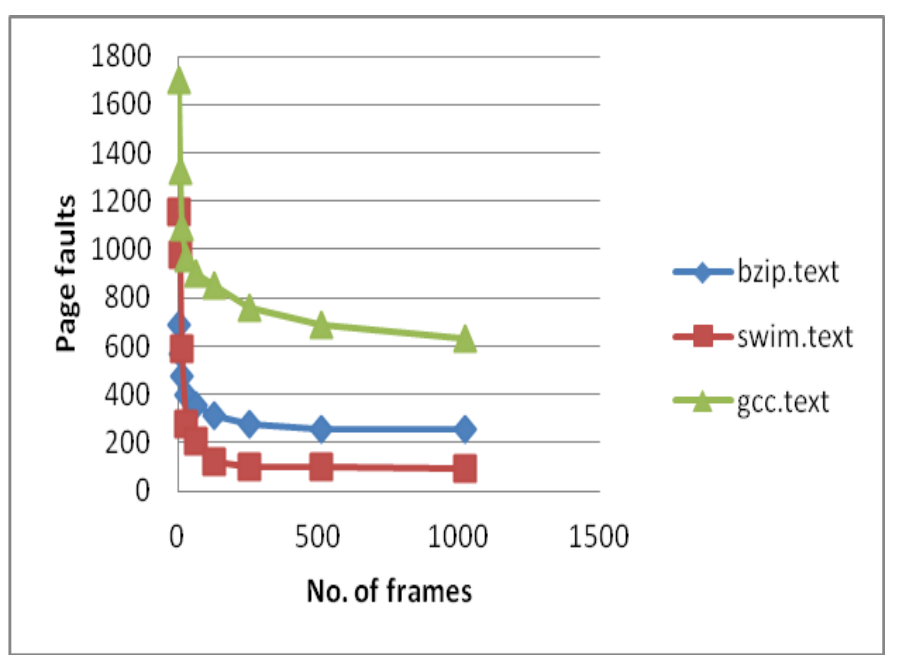

Figure 9 (for SECOND CHANCESet-associative mapping) 
Table10 (Using bzip application)

\begin{tabular}{|c|c|c|c|c|c|c|c|c|c|}
\hline $\begin{array}{l}\text { No. of } \\
\text { frames }\end{array}$ & DIRECT & $\begin{array}{l}\text { No. of Page } \\
\text { faults using } \\
\text { FIFO } \\
\text { Associative }\end{array}$ & $\begin{array}{l}\text { No. of } \\
\text { Page faults } \\
\text { using } \\
\text { FIFO Set } \\
\text { Associative }\end{array}$ & $\begin{array}{l}\text { No. of Page } \\
\text { faults using } \\
\text { LRU } \\
\text { Associative }\end{array}$ & $\begin{array}{l}\text { No. of Page } \\
\text { faults using } \\
\text { LRU Set } \\
\text { Associative }\end{array}$ & $\begin{array}{l}\text { No. of } \\
\text { Page faults } \\
\text { using } \\
\text { Random } \\
\text { Associative }\end{array}$ & $\begin{array}{l}\text { No. of Page } \\
\text { faults using } \\
\text { Random } \\
\text { Set } \\
\text { Associative }\end{array}$ & $\begin{array}{l}\text { No. of Page } \\
\text { faults using } \\
\text { Second } \\
\text { Chance } \\
\text { Associative }\end{array}$ & $\begin{array}{l}\text { No. of Page } \\
\text { faults using } \\
\text { Second } \\
\text { Chance Set } \\
\text { Associative }\end{array}$ \\
\hline 3 & 811 & 719 & 719 & 682 & 682 & 760 & 760 & 688 & 688 \\
\hline 31 & 465 & 378 & 402 & 368 & 378 & 449 & 438 & 367 & 399 \\
\hline 63 & 393 & 329 & 352 & 313 & 335 & 347 & 353 & 317 & 357 \\
\hline 127 & 331 & 278 & 292 & 275 & 287 & 274 & 302 & 281 & 312 \\
\hline 255 & 300 & 244 & 259 & 244 & 257 & 244 & 257 & 244 & 278 \\
\hline
\end{tabular}

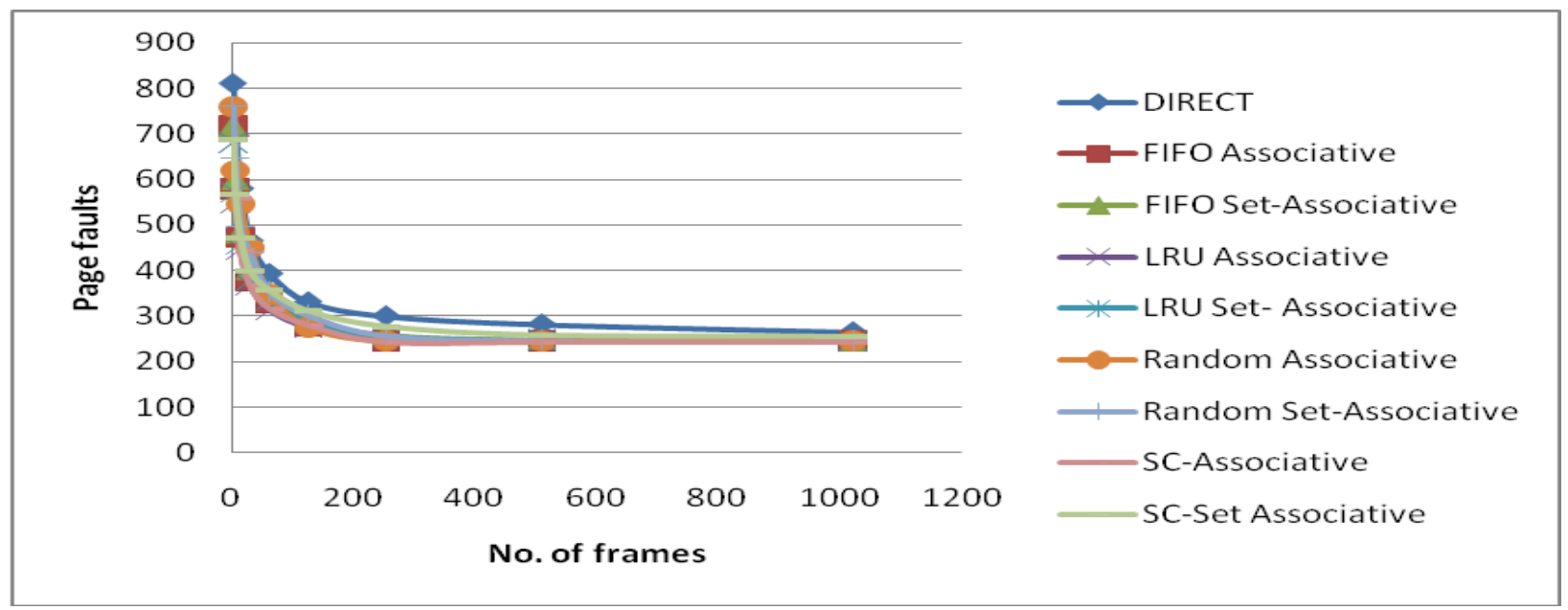

Figure 10 (for bzip application)

Table11 (Using swim application)

\begin{tabular}{|c|c|c|c|c|c|c|c|c|c|}
\hline $\begin{array}{l}\text { No. of } \\
\text { frames }\end{array}$ & DIRECT & $\begin{array}{l}\text { No. of Page } \\
\text { faults using } \\
\text { FIFO } \\
\text { Associative }\end{array}$ & $\begin{array}{l}\text { No. of Page } \\
\text { faults using } \\
\text { FIFO Set } \\
\text { Associative }\end{array}$ & $\begin{array}{l}\text { No. of Page } \\
\text { faults using } \\
\text { LRU } \\
\text { Associative }\end{array}$ & $\begin{array}{l}\text { No. of Page } \\
\text { faults using } \\
\text { LRU Set } \\
\text { Associative }\end{array}$ & $\begin{array}{l}\text { No. of Page } \\
\text { faults using } \\
\text { Random } \\
\text { Associative }\end{array}$ & $\begin{array}{l}\text { No. of Page } \\
\text { faults using } \\
\text { Random } \\
\text { Set } \\
\text { Associative }\end{array}$ & $\begin{array}{l}\text { No. of Page } \\
\text { faults using } \\
\text { Second } \\
\text { Chance } \\
\text { Associative }\end{array}$ & $\begin{array}{l}\text { No. of Page } \\
\text { faults using } \\
\text { Second } \\
\text { Chance Set } \\
\text { Associative }\end{array}$ \\
\hline 3 & 1404 & 1397 & 1397 & 1143 & 1143 & 1425 & 1425 & 1155 & 1155 \\
\hline 31 & 480 & 319 & 355 & 173 & 263 & 304 & 338 & 168 & 277 \\
\hline 63 & 367 & 125 & 221 & 95 & 179 & 118 & 189 & 91 & 206 \\
\hline 127 & 340 & 82 & 132 & 82 & 117 & 82 & 153 & 82 & 121 \\
\hline 255 & 219 & 82 & 98 & 82 & 91 & 82 & 93 & 82 & 101 \\
\hline
\end{tabular}




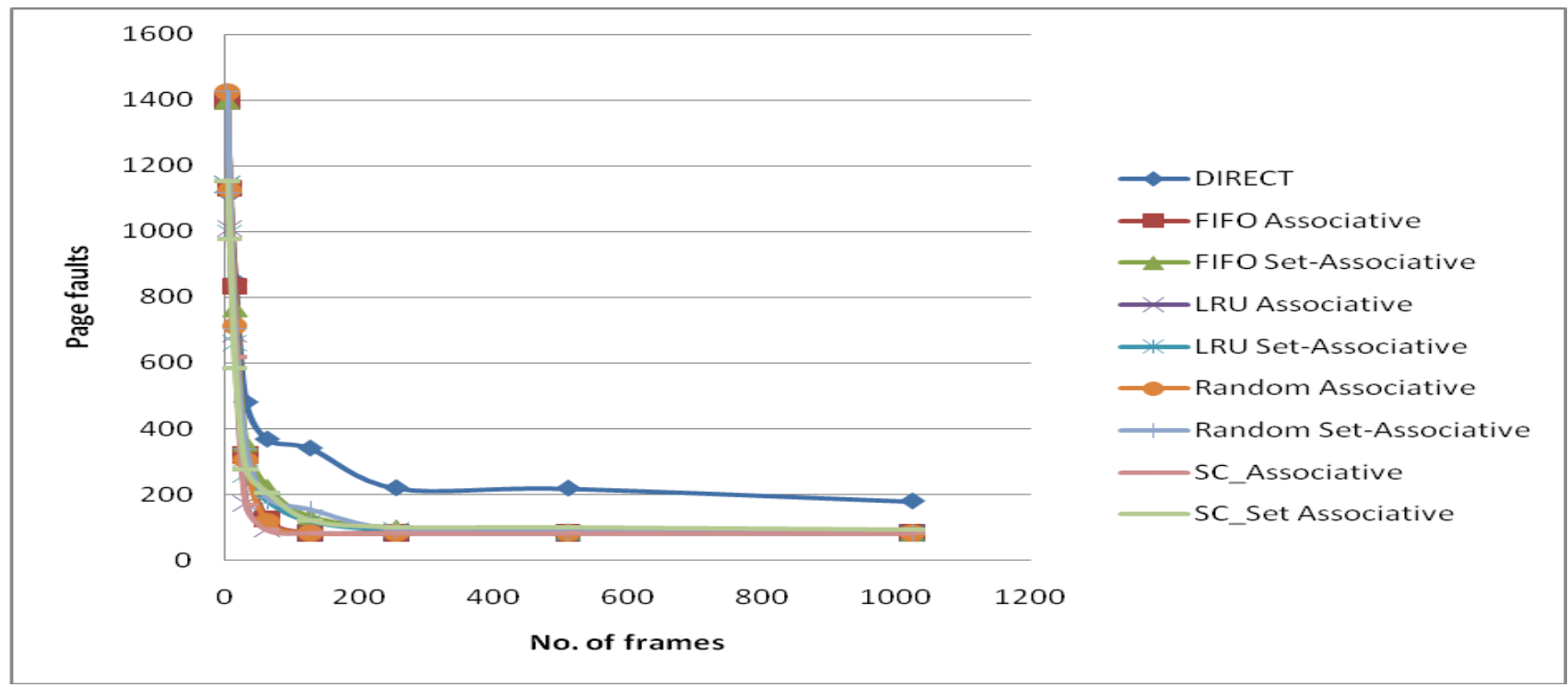

Figure 11 (for swim application)

Table 12 (Using gec application)

\begin{tabular}{|c|c|c|c|c|c|c|c|c|c|}
\hline $\begin{array}{l}\text { No. of } \\
\text { frames }\end{array}$ & DIRECT & $\begin{array}{l}\text { No. of Page } \\
\text { faults } \\
\text { using } \\
\text { FIFO } \\
\text { Associative }\end{array}$ & $\begin{array}{l}\text { No. of } \\
\text { Page faults } \\
\text { using } \\
\text { FIFO Set } \\
\text { Associativ } \\
\text { e }\end{array}$ & $\begin{array}{l}\text { No. of Page } \\
\text { faults using } \\
\text { LRU } \\
\text { Associative }\end{array}$ & $\begin{array}{l}\text { No. of Page } \\
\text { faults } \\
\text { using LRU } \\
\text { Set } \\
\text { Associative }\end{array}$ & $\begin{array}{l}\text { No. of Page } \\
\text { faults } \\
\text { using } \\
\text { Random } \\
\text { Associative }\end{array}$ & $\begin{array}{l}\text { No. of Page } \\
\text { faults using } \\
\text { Random Set } \\
\text { Associative }\end{array}$ & $\begin{array}{l}\text { No. of } \\
\text { Page } \\
\text { faults } \\
\text { using } \\
\text { Second } \\
\text { Chance } \\
\text { Associativ } \\
\text { e }\end{array}$ & $\begin{array}{l}\text { No. of } \\
\text { Page } \\
\text { faults } \\
\text { using } \\
\text { Second } \\
\text { Chance } \\
\text { Set } \\
\text { Associativ } \\
\text { e }\end{array}$ \\
\hline 3 & 1931 & 1826 & 1826 & 1737 & 1737 & 1846 & 1846 & 1699 & 1699 \\
\hline 7 & 1519 & 1415 & 1428 & 1272 & 1310 & 1475 & 1478 & 1253 & 1324 \\
\hline 15 & 1302 & 1121 & 1145 & 1007 & 1054 & 1278 & 1216 & 995 & 1095 \\
\hline 31 & 1141 & 928 & 977 & 886 & 938 & 1140 & 1041 & 893 & 968 \\
\hline 63 & 993 & 858 & 905 & 849 & 888 & 961 & 977 & 849 & 903 \\
\hline 127 & 878 & 828 & 838 & 819 & 830 & 836 & 870 & 820 & 852 \\
\hline 255 & 787 & 803 & 756 & 796 & 752 & 731 & 747 & 693 & 761 \\
\hline 511 & 716 & 575 & 636 & 573 & 630 & 574 & 631 & 574 & 668 \\
\hline 1023 & 672 & 571 & 585 & 571 & 583 & 571 & 578 & 571 & 629 \\
\hline
\end{tabular}

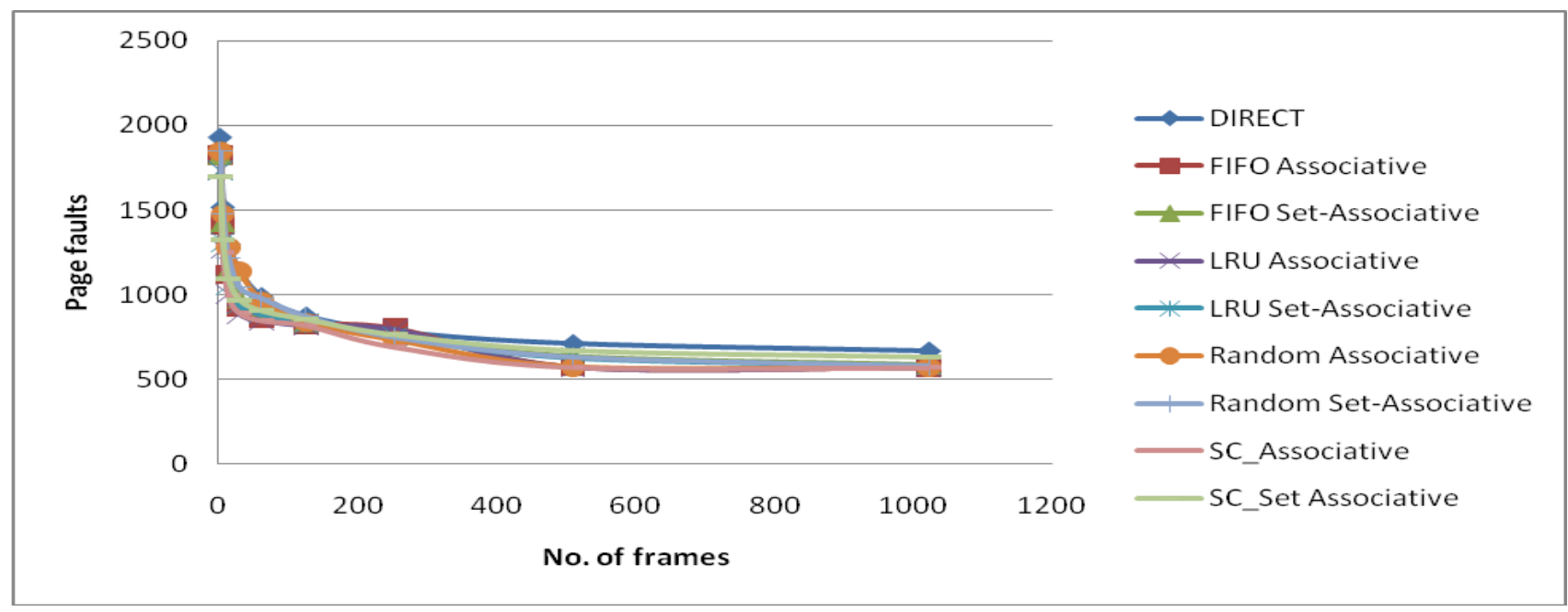




\section{FUTURE SCOPE}

- Simulation can be used for multiprogramming model of operating system.

- Simulation study can be developed to consider complete traces to produce more realistic results.

- Large size of main memory and cache memory can be considered in simulation study.

- This kind of simulation study can be used to compare latest page replacement techniques in cache memory in future.

- Further simulation study can be used to include multiple cache memory levels and execution environment.

- Simulation study proposed in the report provides useful conclusions for the design of future replacement algorithm

\section{CONCLUSION}

It is observed that traces bzip, swim and gcc exhibits different memory access pattern that's why producing different number of page replacement. In all the cache architectures the gcc produces the largest number of page replacement perhaps due to irregular memory access pattern while bzip produces minimum number of page replacement, initially but swim trace gives a rapid decrease in the number of page replacement with increase in number of frames. It is observed that LRU page replacement in associative and set associative gives better performance than other policies in other cache architectures for all the memory traces that's why it can be concluded that SECOND CHANCE associative and LRU associative performance is better than FIFO and RANDOM policies. It is also observed that the performance of SECOND CHANCE associative in cache model is slightly better than LRU in associative cache model.

\section{ACKNOWLEDGEMENTS}

I am thankful to Mr. Ruchin Gupta and my guide Mr. Deepak Chaudhary for their support and cooperation.

\section{REFERENCES}

[1]. Jan Reineke Daniel Grund "Relative Competitive Analysis of Cache Replacement Policies" LCTES'08, June 12-13, 2008, Tucson, Arizona, USA. Copyrightc 2008 ACM.

[2]. S. Jiang, and X. Zhang, "LIRS: An Efficient Policy to improve Buffer Cache Performance",IEEE Transcations on Computers, pp. 939-952, 2005.

[3] S. Albers, S. Arora, and S. Khanna, "Page replacement for general caching problems," Proceedings of the 10th Annual ACM-SIAM Symposium on Discrete Algorithms, pp. 31-40, 1999.

[4]. Hameed, F., L. Bauer and J. Henkel, 2013. "Dynamic cache management in multi-core architectures through run-time adaptation. Proceedings of the Design, Automation and Test" in Europe Conference and Exhibition, Mar. 12-16, IEEE Xplore Press, Dresden, pp: 485-490. DOI: 10.1109/DATE.2012.6176518

[5]. S.Irani, "Page Replacement with Multi-Size Pages and Applications to Web Caching," Proc.29th Ann, ACM symp. Theory of Computing, pp. 701-710, 1997. [6] E. J. O'Neil, P. E. O'Neil, and G. Weikum, "an Optimality Proof of the LRU-K page Replacement Algorithm." J.ACM, vol. 46, no.1, pp. 92-112, 1999.
[6].Debabala Swain, Bijay K Paikray, Debabrata Swain,"AWRP: Adaptive Weight Ranking Policy for Improving Cache Performance", Journal of Computing, vol-3, Issue-2, February 2011.

[7]. Kaveh Samiee and GholamAli Rezai Rad, "WRP: Weighting Replacement Policy to Improve Cache Performance," International Symposium on Computer Science and its Application, IEEE, 2008.

[8].Yogesh Niranjan, Shailendra Tiwari "Design and Implementation of Page Replacement Algorithm for Web Proxy Caching", Int.J.Computer Technology \& Applications, Vol 4 (2),221-225 IJCTA | Mar-Apr 2013.

[9].C. Aggarwal, J. L. Wolf, and P. S. Yu. "Caching on the WorldWideWeb," In IEEE Transactions on Knowledge and Data Engineering, vol. 11, pp. 94-107, 1999.

[10].Nimrod Megiddo, Dharmendra, S. Modha IBM Almaden Research Center Outperforming LRU with an Adaptive Replacement Cache Algorithm, Published by the IEEE Computer Society, 0018-9162/04/\$20.00 @ 2004 IEEE.

[11]. S.M. Shamsheer Daula, Dr. K.E Sreenivasa Murthy, G Amjad Khan "A Throughput Analysis on Page Replacement Algorithms in Cache Memory Management", International Journal of Engineering Research and Applications (IJERA) ISSN: 2248-9622 Vol. 2, Issue 2, pp.126-130.

[12].John Dilley, Martine Arlitt and Stephane Perret "Enhancement and Validation of Squid's Cache Replacement Policy" Internet Systems and Applications Laboratory HP Laboratories Palo Alto HPL- 1999-69, May 2009.

[13].Michael Factor, Assaf Schuster, Gala Yadgar, "Multilevel Cache Management Based on Application Hints" Technion- Computer Science Department Technical Report CS-2006.

[14]. Amit S. Chavan, Kartik R. Nayak, Keval D. Vora, Manish D. Purohit and Pramila M. Chawan "A Comparison of Page Replacement Algorithms" IACSIT Vol.3, No.2, April 201.

[15]. A. S. Tanenbaum and A. S. Woodhull, Operating Systems: Design and Implementation. Prentice-Hall, 1997.

[16] Vinit A. Kakde, Sanjay K. Mishra, " Effective Web Cache Algorithm," International Journal of Electronics, Communication \& Soft Computing Science and Engineering (IJECSCSE) Volume 1, Issue 1.

[17]http://infocenter.arm.com/help/index.jsp?topic=/com.arm. doc.set.cortexr/index.html

[18] Development of a Virtual Memory Simulator to Analyze the Goodness of Page Replacement Algorithms Fadi N. , Sibai, Maria Ma, David A. Lill

[19]. Debabrata Swain, Bancha Nidhi Dash “ Analysis and Predictability of Page Replacement Techniques towards Optimized Performance"IRCTITC 2011 Proceedings published in International Journal of Computer Applications ${ }^{\circledR}$ (IJCA). 